\title{
A Meta-Analysis of the Effect of Small-Sided Games on the Repeated Sprint Ability in Soccer
}

\author{
P. L. Morera-Siercovich a (iDand J. Moncada-Jiménez ${ }^{\text {a,b* }}$ (D) \\ a School of Physical Education and Sports, University of Costa Rica, Costa Rica \\ ${ }^{b}$ Human Movement Sciences Research Center (CIMOHU), University of Costa Rica, Costa Rica \\ *Corresponding author Phone: +506 25112909. E-mail: jose.moncada@ucr.ac.cr \\ DOI: https://doi.org/10.34256/ijpefs2048
}

Received: 07-11-2020, Accepted:15-12-2020; Published: 18-12-2020

Abstract: To determine the effect of small-sided games (SSG) on the repeated sprint ability (RSA) in male soccer players. A meta-analysis was conducted in which studies were selected from the electronic databases Medline, SPORTDiscus, Google Scholar, and PubMed. Results: Six studies were included and 44 effect sizes (ES) were computed from 116 men (age $=18.0 \pm 2.8 \mathrm{yr}$., height $=175.8 \pm 3.3 \mathrm{~cm}$, weight $=68.6 \pm 5.6 \mathrm{~kg}$, body mass index $\left.[\mathrm{BMI}]=22.3 \pm 1.1 \mathrm{~kg} \cdot \mathrm{m}^{2}, \mathrm{VO}_{2} \mathrm{max}=56.9 \pm 2.1 \mathrm{ml} \cdot \mathrm{kg}^{-1} \cdot \mathrm{min}^{-1}\right)$. The SSG training improved the overall RSA performance $(E S=-.54,95 \% C I=-.89,-.20, p<.05)$, reduced RSA total time $(E S=-.41,95 \% C I=-.81,-.01, p<$ $.05)$, and fatigue index ( $E S=-.83,95 \% C I=-1.65,-.02, p<0.05)$. Moderator analysis showed that the fatigue index is impaired when several sessions/week are performed $\left(\beta=.69,95 \% C I=.29,1.10, R^{2}=82.9, p=.001\right)$ and is enhanced when the duration of the intervention is extended over several weeks $(\beta=-.25,95 \% C I=-.47$, $\left..03, R^{2}=56.6, p=.05\right)$. The methodological use of SSG enhances the capacity of repeated sprints, while technical and tactical elements are worked concomitantly.

Keywords: Soccer, Game, Training, Sprint, Performance.

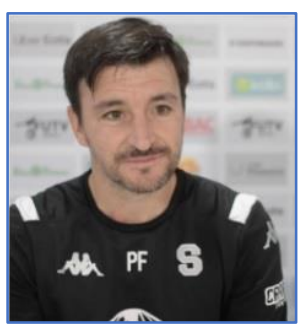

Pier L. Morera-Siercovich holds a Bachelor's degree in Physical Education from the University of Costa Rica. He is currently a student in the graduate program in Human Movement Sciences at the University of Costa Rica and the head performance specialist of the Saprissa S.A.D. football team of the professional league in Costa Rica. The professional experience as head performance specialist has led him to become champion with football teams of the professional league in Costa Rica in several occasions.

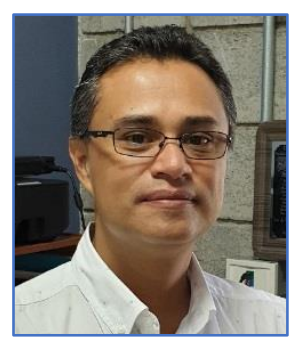

José Moncada-Jiménez holds a Ph.D. in Biomedical Sciences from the University of Costa Rica, a post-doctoral internship at Baylor University, in Texas, USA, and postgraduate studies at The Ohio State University, in Ohio, USA. He also holds a M.Sc. in Movement Sciences with a specialization in Exercise Physiology from Springfield College, in Massachusetts, USA. He is the founder of the Human Movement Sciences
Research Center (CIMOHU) of the Vice-rectory for Research of the University of Costa Rica. He has taught courses in research methods, statistical analysis, exercise physiology, and measurement and evaluation, among others. He is currently a full-time professor and researcher at the University of Costa Rica.

\section{Introduction}

In team sports, athletes must repeatedly perform maximal efforts combined with short recovery intervals (i.e., moderate or low-intensity activity, or even complete rest) [1, 2]. In football association (soccer), players perform sprints at a very highintensity and short duration (< 10-s) during any normal action of the game. These movements are interspersed with brief recovery periods that do not exceed 60-s [2], and these efforts consist, among others, of sprints, turns, jumps, and one-on-one duels. These activities are often carried out at decisive moments during the game; thus, players must be prepared to perform at the highest level and trainers 
must be attentive to develop their fitness during the training sessions.

The basic movement pattern in soccer requires the development of explosive strength and power; and successive actions during the game will cause a performance decrease as a result of transient fatigue [1]. This capacity to repeat efforts of high-intensity and short-duration after brief recovery periods has been called the repeated sprint ability (RSA) [2-5]. In soccer, the RSA is a good predictor of physical performance in highly trained professional players $[4,6]$. Training that includes RSA increases maximal oxygen consumption $\left(\mathrm{VO}_{2} \mathrm{max}\right)$, recovery capacity, strength, and speed [3, $7,8]$. Therefore, it is inferred that the soccer player who possesses an adequate RSA can produce high muscular power during the first sprint and can repeat this effort on successive occasions with the least possible loss of performance.

The optimal design and implementation of training strategies aimed at improving the RSA are of great interest to soccer coaches and players, and like any other physical capacity that can be developed through different methodologies, it is essential that it is governed by the principle of specificity because other important components of soccer are often neglected, such as technical and tactical skills, perception skills, visual scanning and decision making. In this context, small-sided games (SSG) have attracted the attention of soccer coaches due to the physiological demands it imposes, due to the effects on physical development $[9,10]$. The SSG also simulates specific soccer movement patterns and force players to improve their technical profiles $[9,11]$.

The SSGs are defined as training tasks whose structure is similar to that of a real game since they are carried out in small areas of the field with adapted rules and a reduced number of players compared to official games [1]. To design SSGs, a large number of variables have been studied that can be manipulated to prescribe different work sessions and influence the intensity of the game. These variables include the relative area per player [12], field size [12, 13], field orientation [13], number of players $[14,15]$, tactical behavior [16], the work-to-rest ratio $[13,17]$, specific goals, and the end of the play or ball possession [16, 17]. Rules modifications [18], playing with or without a goalkeeper [19], the presence of "wildcard" players $[10,20]$, and the coach's feedback $[1,7,19]$, are among other variables commonly reported. The vast majority of these studies have described the acute or immediate effect of SSGs.
In experimental studies, positive outcomes have been reported when using SSG as an intervention for the development of physical qualities [1, 18, 20]. For example, Bujalance-Moreno, García-Pinillos [1], conducted a six-week training program with recreational soccer players to determine the effects on RSA. The participants were randomly assigned to a control group, which performed activities consisting of technical-tactical actions and prevention exercises, and an experimental group, which trained on two SSG formats ( 2 vs. 2 players, 4 vs. 4 players). The results showed that the group that performed SSG improved the RSA.

The RSA is assessed by four components that map an athlete's functional capacity: a) best time, b) total time (i.e., the sum of times), c) fatigue index, and d) average of sprints. The best time is the shortest time achieved in the sprints carried out. The total time refers to the sum of all the times recorded during the completion of the test. This is the overall result of the test and can be considered as an indicator of the ability to perform intermittent maximum intensity exercise. The fatigue index is calculated in different ways [21, 22] and is intended to provide information related to the percentage loss or decrease in performance during the execution of repeated sprints. Although the reliability of the index has been questioned [22], this measure represents the degree of fatigue and the individual soccer player's ability to recover fast. Among the fatigue indices described in the literature is the Bangsbo [23] index, which consists of obtaining the difference between the worst and the best time. The Wragg, Maxwell [24] index is the difference between the mean of the two worst and the two best times. However, the most frequently used index in RSA studies is that of Fitzsimons, Dawson [25], since it provides information about how the performance decrease occurs throughout the test. The last variable usually considered for analysis is the sprint average, which is the mean of the summation of all times.

Safania, Alizadeh [18], studied amateur soccer level players participating in SSG training and found that activities such as 2 vs. 2, 3 vs. 3, and 4 vs. 4 players increased significantly the $\mathrm{VO}_{2}$ max, maximum power, and RSA as measured by the fatigue index. Similarly, a study by Eniseler, Şahan [26] on junior category players, compared SSG (3 vs. 3 players without a goalkeeper, area $=18 \times 30 \mathrm{~m}, 4 \times 3 \mathrm{~min}$ ) to a repeated sprint training program. Players in both groups improved the RSA fatigue index, although the highest scores were obtained in the SSG group. 
Therefore, this method is recommended not only because it seems to be more effective, but also because it is based on technical aspects of soccer. Based on this context, this study aimed to metaanalyze the effect of SSG on the ability to perform RSA in soccer players and to identify variables that potentially moderate this effect.

\section{Methodology}

\subsection{Overview}

This study followed the methodologies to complete a systematic review and meta-analysis suggested by the Preferred Reporting Items for Systemic Reviews and Meta-analyses (PRISMA) [27].

\subsection{Eligibility criteria}

Studies that met the following criteria were included: a) amateur or elite level male soccer players, b) age $\geq 14$ yr., c) different types of SSG interventions, d) RSA pre-to post-test comparison, e) experimental or quasi-experimental design, f) intervention $\geq 4$ weeks, g) reported the mean, standard deviation (SD) and sample size per group, h) articles published in English no more than 10 years old, and $h$ ) a score $\geq 6$ as the criterion for studies with low risk of bias based on the Physiotherapy Evidence Database (PEDro) Scale [28].

\subsection{Information sources and search strategy}

The systematic search strategy for the articles was carried out between the months of September and November 2019 in the MEDLINE, SPORTDiscus, Google Scholar, and PubMed electronic databases. The following keywords were used, either by a single word or in a Boolean combination: RSA or repeated-sprint training or high-intensity training, small-sided games, and soccer.

\subsection{Study records and selection}

All studies to potentially be screened were imported into Zotero software (Corporation for Digital Scholarship, VA). One author then removed duplicates both electronically and manually. Then, the authors selected all studies and the full report for each article was obtained for all titles and abstracts that appeared to meet the inclusion criteria. Reasons for exclusion were coded as one of the following: 1) duplicates, 2) missing or incomplete descriptive statistics, 3) inappropriate research design, 4) language different to English, and 5) abstracts. Based on the final number of studies to be included, the overall precision of the searches was calculated by dividing the number of studies included by the total number of studies screened after removing duplicates, and then the number needed to read (NNR) was computed as the inverse of the precision [29].

\subsection{Data abstraction}

Titles and/or abstracts of studies retrieved using the search strategy, and those from additional sources were screened to identify studies that potentially meet the inclusion criteria outlined above. The full text of these potentially eligible studies were retrieved and assessed for eligibility, and the data were exported to a standardized, pre-piloted Excel (Microsoft Corporation, Redmond, WA) spreadsheet used to extract data from the included studies for assessment of study quality and evidence synthesis.

If available, the extracted information included: a) participant characteristics (e.g., age, body height, body weight, body mass index [BMI], $\mathrm{VO}_{2}$ max, b) study design: experimental group or "traditional" training group (any activity or exercise that does not include SSG, whether it was continuous running, technical-tactical work, preventive work), c) number sessions (per week, total number of sessions during the intervention), d) load dosage (working time per session, working time per week, total time during the intervention), e) dimensions of the area (field width, field length, ratio of $\mathrm{m}^{2}$ per player within the reduced space), and f) the primary outcome RSA (best time, average, fatigue index, total time). As there are SSG structured with many variants (e.g., distance, number of players, series, repetitions, time, and space), each of the variables was averaged. Missing data were requested from study authors.

\subsection{Risk of bias assessment in individual studies}

The PEDro scale [28] was used to assess the risk of bias and the methodological quality of eligible studies included in the meta-analysis. This scale assesses the internal validity of the study on a scale from 0 (high risk of bias) to 10 (low risk of bias). In this study selection process, data were extracted by one person (PM), using a data coding sheet, which was reviewed by another person (JM). Disagreements were resolved through discussion between the two researchers. 
2.7 Data synthesis and calculation of effect sizes

The effect size (ES) was calculated as the difference between means according to the methodology proposed by Borenstein, Hedges [30]. For the calculation, the initial score (pre-test) of the RSA was compared with the final score (post-test) after the SSG intervention took place. For interpretation purposes, an ES with a negative sign in the RSA components means an improvement depending on the treatment since it is measured by time, and the longer it is, the worse the performance. The ESs were interpreted as trivial (0-.19), small (.20$.49)$, moderate (.50-.79), and large ( $\geq .80)$ [31]. The ES represents the magnitude of the effect of SSG on RSA and an individual ES was calculated at the intragroup level (difference from pre-test to post-test in each group). Once the individual ES had been calculated, the global ES and the 95\% confidence interval $(95 \% \mathrm{CI})$ were computed. For the analysis, the random effects model was used, which assumes that ESs vary between studies [30, 32].

\subsection{Meta-biases}

The small-study effects (i.e., publication bias) were assessed following current recommendations [33, 34]. The degree of heterogeneity of the studies was analyzed through Cochran's Q test [35], and the degree of consistency between studies was calculated through the $\mathrm{I}^{2}$ test, which was interpreted as low ( $\leq$ $25 \%)$, moderate (26-74\%), and high ( $\geq 75 \%$ ) [36]. The effect of the studies with small samples was determined by the Doi plot [33] and the Luis FuruyaKanamori (LFK) index [33] to detect asymmetry as Egger's regression loses statistical power in small samples [37]. The LFK values outside the interval -1 and 1 were considered consistent with asymmetry (i.e., publication bias) [38]. An a level $\leq .05 \%$ and $95 \%$ confidence intervals $(95 \% \mathrm{CI})$ that did not include zero (0) were considered to represent statistically significant small-study effects.

\subsection{Software used for data synthesis}

All data were analyzed using Microsoft Excel v.2010 (Microsoft Corporation, Redmond, WA) and the Meta XL v.5.3, 2016 add-in software for Excel (EpiGear Intl., Queensland, Australia). The analysis of moderating variables of the ES of the fatigue index component of the SRA was analyzed with a metaregression using the OpenMEE software [39].

\section{Results and Discussion}

\subsection{Study characteristics}

A process that depicts the search process for study selection is shown in figure 1 . After initially identifying 388 citations and removing 135 duplicates both electronically and manually, 253 citations were screened. Of these, 69 studies met the criteria for inclusion. Three studies were unrelated to soccer, and 57 studies did not include SSG but interventions focused on running and drills where players did not use the ball. The precision of the search, excluding duplicates, was $2.4 \%$ while the NNR was 42 .

\subsection{Participant characteristics}

The selected studies included a total of 116 male soccer players (age $=18.0 \pm 2.8 \mathrm{yr}$., body height $=175.8 \pm 3.3 \mathrm{~cm}$, body weight $=68.6 \pm 5.6 \mathrm{~kg}$, BMI $=22.3 \pm 1.1 \mathrm{~kg} \cdot \mathrm{m}^{2}, \mathrm{VO}_{2} \max =56.9 \pm 2.1 \mathrm{ml} \cdot \mathrm{kg}^{-1} \cdot \min$ $\left.{ }^{1}\right)$. Of these participants, 76 players used SSG as an intervention for the development of RSA, and 19 trained in continuous or intermittent racing situations (i.e., "traditional" training) (Table 1).

\subsection{Risk of bias assessment}

Each study was subjected to an assessment of the risk of bias and methodological quality using the PEDro Scale (Table 2). Both the risk of bias and the methodological quality was moderate (Mean $=6.3 \pm .5$ pts.).

\subsection{Data synthesis}

With the selected studies, a total of 44 ES were calculated, of which 25 resulted from SSG, eight from "traditional" training, and 11 concerning the moderating variables of the experimental group (i.e., SSG).

The ES for the best time was not significant $(\mathrm{ES}=-.38,95 \% \mathrm{CI}=-.94, .18)$. $\mathrm{A}$ moderate bias $\left(\mathrm{I}^{2}=\right.$ $65 \%)$, homogeneity $(\mathrm{Q}=14.10, \mathrm{p}=.01$, Figure $2 \mathrm{a})$, and no asymmetry of the ES (LFK index $=-.34$, Figure 2b) were found. Average sprint ES was not significant $(\mathrm{ES}=-.51,95 \% \mathrm{CI}=-1.60, .57)$. There was a high inconsistency $\left(\mathrm{I}^{2}=82 \%\right)$, homogeneity $(\mathrm{Q}=16.59, \mathrm{p}$ $\leq .001$, Figure 3a), and little asymmetry in the ES (LFK index $=-1.55$, Figure $3 b$ ). The ES for the fatigue index was significant $(\mathrm{ES}=-.83,95 \% \mathrm{CI}=-1.65,-.02)$. $\mathrm{A}$ high bias $\left(\mathrm{I}^{2}=82 \%\right)$, homogeneity $(\mathrm{Q}=27.23$, $\mathrm{p} \leq$ .001 , Figure 4a), and no asymmetry in the ES (LFK index $=-.91$, Figure $4 b$ ) were found. The ES for the total time was significant $(\mathrm{ES}=-.41,95 \% \mathrm{CI}=-.81$, 
$.01)$. There was consistency in the studies $\left(\mathrm{I}^{2}=0 \%\right)$, homogeneity $(\mathrm{Q}=1.89, \mathrm{p}=.60$, Figure $5 \mathrm{a})$, and little asymmetry in the ES (LFK index $=1.36$, Figure $5 b$ ). The ES for all subgroups was significant (ES $=-.54$, $95 \% \mathrm{CI}=-.89,-.20) . \mathrm{A}$ moderate bias $\left(\mathrm{I}^{2}=70 \%\right)$, homogeneity $(\mathrm{Q}=63.99, \mathrm{p} \leq .001$, Figure $6 \mathrm{a})$, and no asymmetry in the ES (LFK index $=-.28$, Figure $6 b$ ) were found.
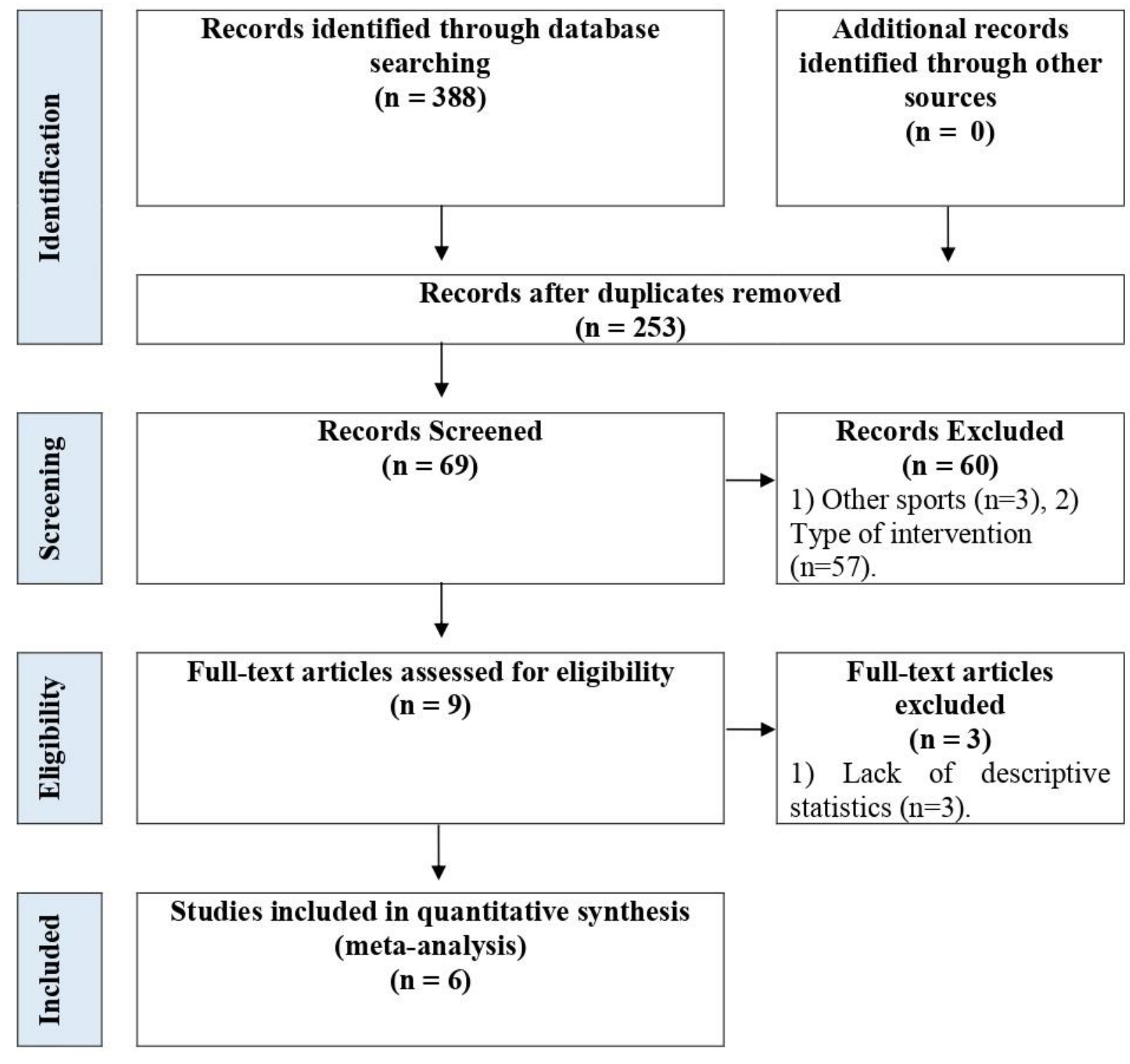

$\rightarrow \begin{aligned} & \begin{array}{c}\text { Full-text articles } \\ \text { excluded } \\ (\mathbf{n}=3)\end{array} \\ & \text { 1) Lack of descriptive } \\ & \text { statistics }(n=3) .\end{aligned}$

Figure 1. Flow diagram depicting the search process.

Significant ESs were followed by a metaregression to identify the contribution of possible moderating variables of the effect of SSG on the fatigue index in RSA (Table 3). The variables that did not contribute significantly to moderating the effect were the number of total sessions, the recovery time/series, the field size, and the relative area per player ( $p>.05$ for all).
The purpose of the study was to determine the effect of SSG on the RSA in male soccer players. Our findings must be carefully considered given the low number of studies included for analysis and the large heterogeneity found between studies. The main finding was that male soccer players training in reduced spaces improved their ability to perform repeated sprints. The overall ES was significant and demonstrated a moderate effect on the RSA. The present meta-analysis confirms that SSGs have a direct 
impact on the development of RSA, a basic skill required in soccer $[2,40-42]$.

Table 1 Main Characteristics of the studies meta-analyzed $(n=6)$

\begin{tabular}{|c|c|c|c|c|c|}
\hline Study & Sample & $\mathbf{n}$ & Season & SSG characteristics & RSA outcome \\
\hline $\begin{array}{l}\text { Owen et al. } \\
2012\end{array}$ & $\begin{array}{l}\text { Premier } \\
\text { League } \\
\text { Scotland }\end{array}$ & 15 & Competitive & $\begin{array}{l}3 \text { vs. } 3 \text { with goalkeeper } \\
125 \mathrm{~m}^{2}=\text { relative area } \\
\text { Workload: } 8 \times 3 \mathrm{~min} / 2 \mathrm{~min} \\
\text { recovery }\end{array}$ & $\begin{array}{l}\uparrow \quad \mathrm{RSA} \% \text { fatigue } \\
\text { index } \\
\uparrow \mathrm{RSA} \text { total time }\end{array}$ \\
\hline $\begin{array}{l}\text { Eniseler et al. } \\
2017\end{array}$ & U-18 players & 19 & $\begin{array}{l}\text { Pre- } \\
\text { competitive }\end{array}$ & $\begin{array}{l}3 \text { vs. } 3 \text { no goalkeeper } \\
90 \mathrm{~m}^{2}=\text { relative area } \\
\text { Workload: } 4 \text { × } 3 \mathrm{~min} / 4 \mathrm{~min} \\
\text { recovery }\end{array}$ & $\uparrow$ RSA \%fatigue index \\
\hline $\begin{array}{l}\text { Rodriguez et } \\
\text { al. } 2017\end{array}$ & $\begin{array}{l}\mathrm{U}-18 \\
\text { amateur } \\
\text { players }\end{array}$ & 24 & $\begin{array}{l}\text { Pre- } \\
\text { competitive }\end{array}$ & $\begin{array}{l}\text { Different formats: } 2 \text { vs. } 2,3 \\
\text { vs. } 3,4 \text { vs. } 4,5 . \text { vs. } 5,6 \text { vs. } \\
6,7 \text { vs. } 7 \\
94-150 \mathrm{~m}^{2}=\text { relative area } \\
\text { Workload: } 4 \text { x } 12 \mathrm{~min} / 2 \mathrm{~min} \\
\text { recovery }\end{array}$ & $\begin{array}{l}2 \text { subgroups according } \\
\text { to pre-test: } \\
\text { a. Better: no change } \\
\text { b. Worst: } \uparrow \text { RSA total } \\
\text { time } \\
\begin{array}{ll} & \uparrow \text { RSA best } \\
& \uparrow \mathrm{RSA}\end{array} \\
\text { average }\end{array}$ \\
\hline $\begin{array}{l}\text { Hill-Haas et al. } \\
2009\end{array}$ & U-15 players & 19 & Competitive & $\begin{array}{l}\text { Different formats: } 4 \text { vs. } 4,4 \\
\text { vs. } 4+\text { goalkeeper, } 6 \text { vs. } 6 \text {, } \\
6 \text { vs. } 6+\text { goalkeeper, } 8 \text { vs. } 8 \\
75-165 \mathrm{~m}^{2}=\text { relative area } \\
\text { Workload: } 3 \text { x } 10 \mathrm{~min} / 2 \mathrm{~min} \\
\text { recovery }\end{array}$ & No change \\
\hline $\begin{array}{l}\text { Dello Iacono } \\
\text { et al. } 2019\end{array}$ & $\begin{array}{l}\text { U-19 } \\
\text { England and } \\
\text { UEFA } \\
\text { leagues }\end{array}$ & 20 & Competitive & $\begin{array}{l}5 \text { vs. } 5 \text { with goalkeeper } \\
126 \mathrm{~m}^{2}=\text { relative area } \\
\text { Workload: } 4 \text { x } 4 \mathrm{~min} / 2 \mathrm{~min} \\
\text { recovery }\end{array}$ & $\begin{array}{ll}\uparrow & \text { RSA \%fatigue index } \\
\uparrow & \text { RSA best } \\
\uparrow & \text { RSA average }\end{array}$ \\
\hline $\begin{array}{l}\text { Jensen et al. } \\
2009\end{array}$ & $\begin{array}{l}\text { U-20 } \\
\text { professional } \\
\text { Scandinavian }\end{array}$ & 19 & $\begin{array}{l}\text { Pre- } \\
\text { competitive }\end{array}$ & $\begin{array}{l}\text { Does not define format } \\
\text { Workload: } 4 \text { × } 3 \mathrm{~min} / 1.5 \mathrm{~min} \\
\text { recovery }\end{array}$ & $\uparrow \quad$ RSA \%fatigue index \\
\hline
\end{tabular}

Table 2 Quality evaluation of the studies using the PEDro Scale.

\begin{tabular}{|l|c|c|c|c|c|c|c|c|c|c|c|c|c|}
\hline Reference & Year & A & B & C & D & E & F & G & H & I & J & K & Score \\
\hline Owen et al. & 2012 & 1 & 0 & 0 & 1 & 0 & 0 & 0 & 1 & 1 & 1 & 1 & 6 \\
\hline Eniseler et al. & 2017 & 1 & 1 & 0 & 1 & 0 & 0 & 0 & 1 & 1 & 1 & 1 & 7 \\
\hline Rodríguez et al. & 2017 & 1 & 0 & 0 & 1 & 0 & 0 & 0 & 1 & 1 & 1 & 1 & 6 \\
\hline Hill-Haas et al. & 2009 & 1 & 1 & 0 & 1 & 0 & 0 & 0 & 0 & 1 & 1 & 1 & 6 \\
\hline Dello Iacono et al. & 2019 & 1 & 1 & 0 & 1 & 0 & 0 & 0 & 1 & 1 & 1 & 1 & 7 \\
\hline Jensen et al. & 2009 & 1 & 0 & 0 & 1 & 0 & 0 & 0 & 1 & 1 & 1 & 1 & 6 \\
\hline
\end{tabular}

Note: A) Eligibility criteria were specified, B) subjects were randomly allocated to groups, C) Allocation was concealed, D) The groups were similar at baseline regarding the most important prognostic indicators, E) there was blinding of all subjects, F) There was blinding of all therapists who administered the therapy, G) There was blinding of all assessors who measured at least one key outcome, H) Measures of at least one key outcome were obtained from more than $85 \%$ of the subjects initially allocated to groups, I) All subjects for whom outcome measures were available received the treatment or control condition as allocated, J) The results of between-group statistical comparisons are reported for at least one key outcome, K) The study provides both point measures and measures of variability for at least one key outcome. 
(a)

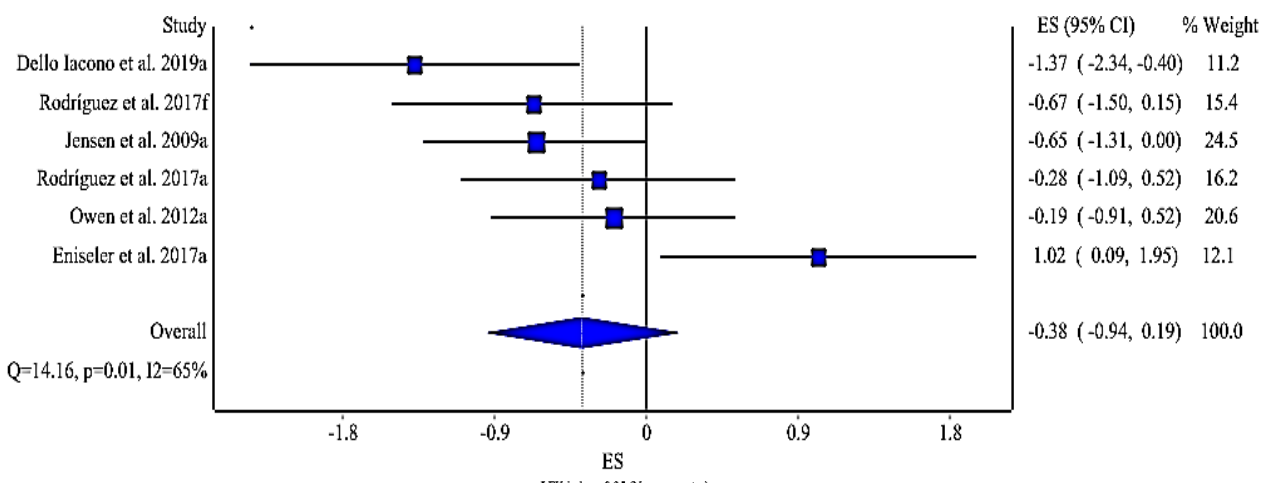

(b)

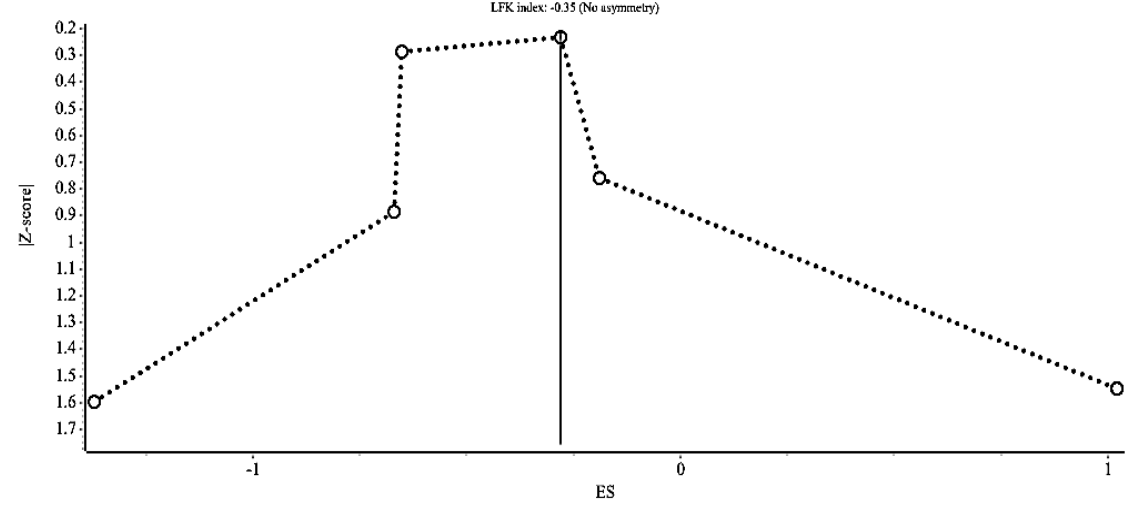

Figure 2 Forest (a) and DOI plot (b) for the best time.

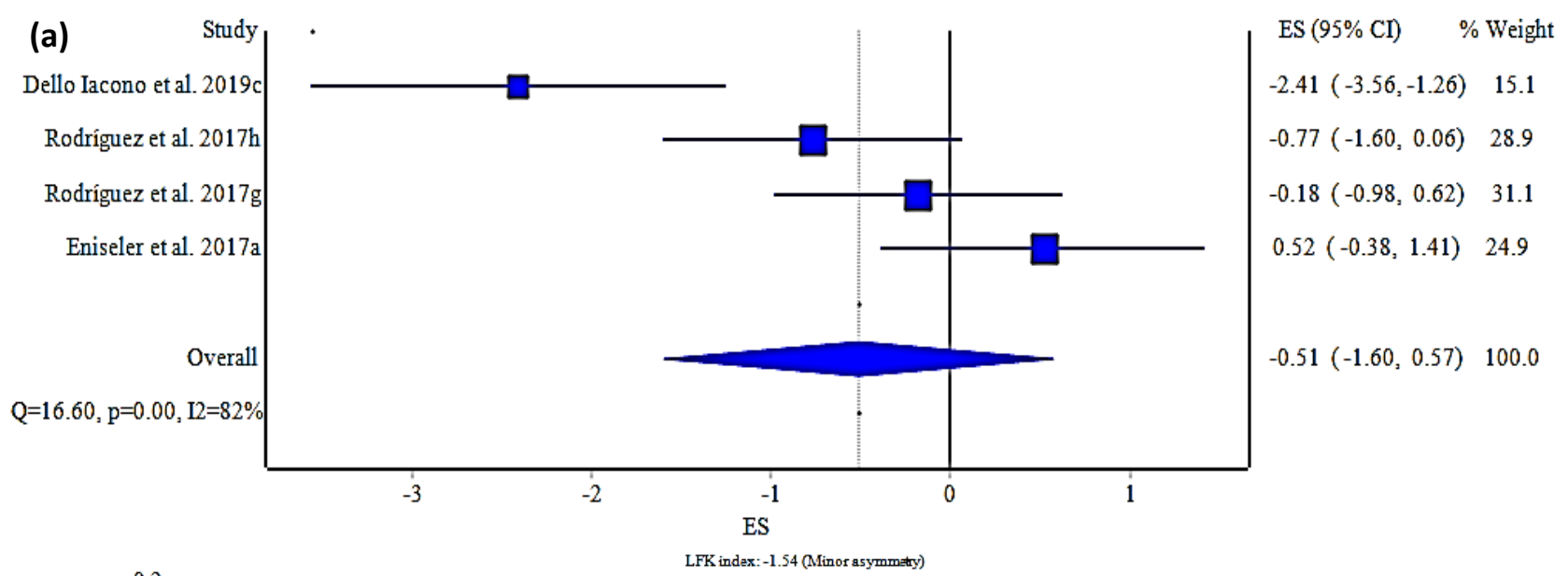

(b)

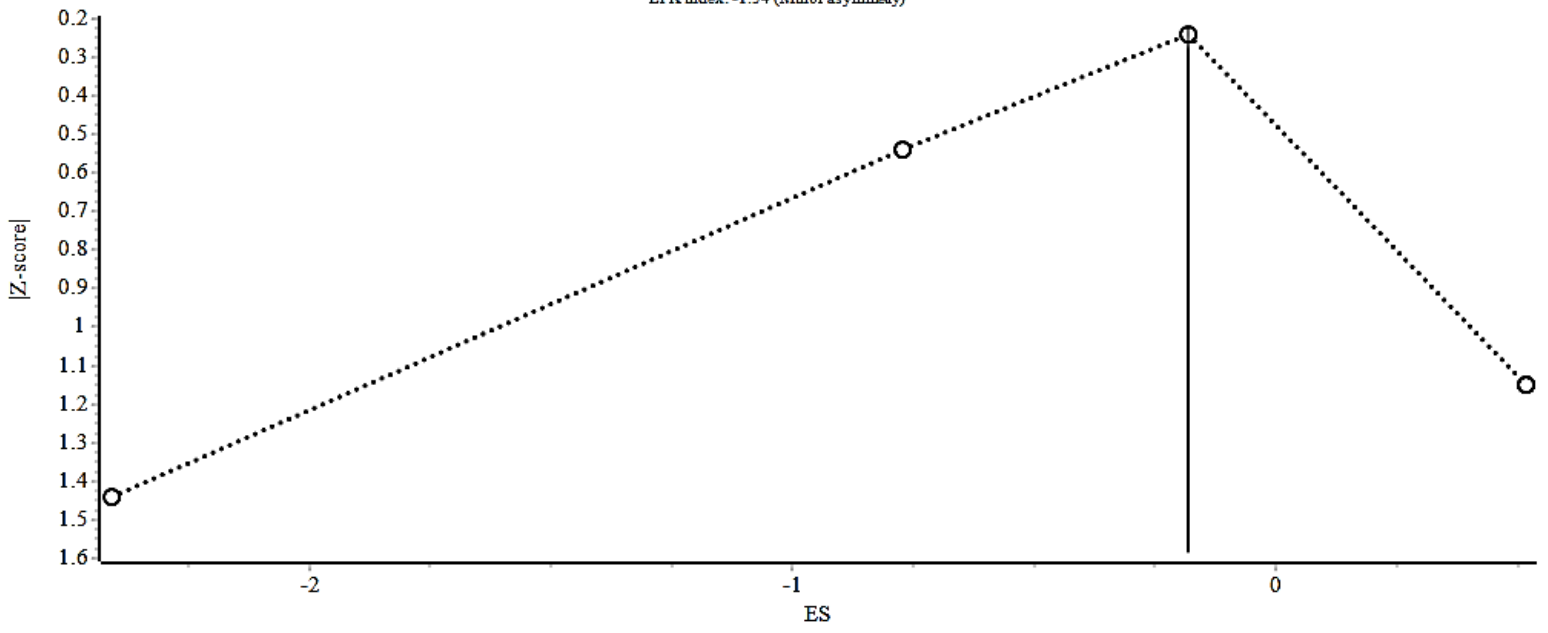

Figure 3 Forest (a) and Doi (b) plots for average sprint time. 


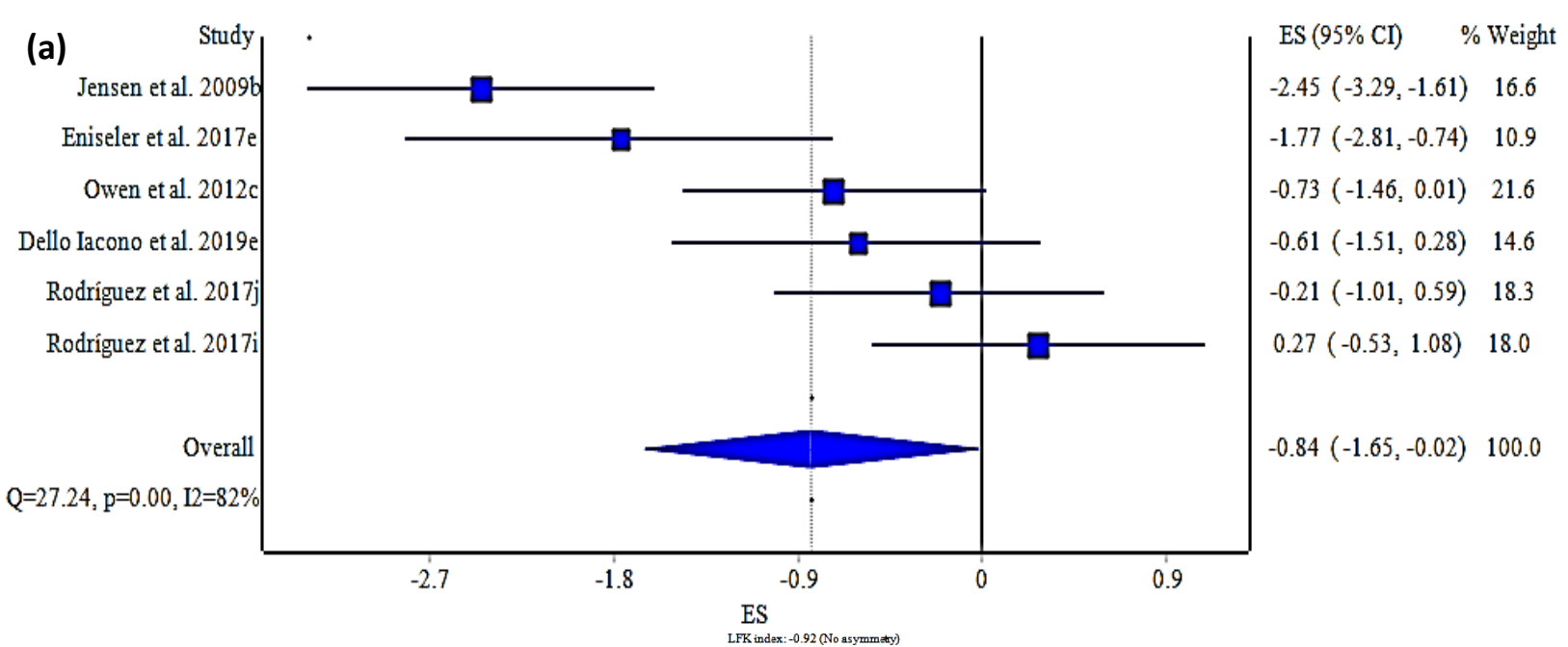

(b)

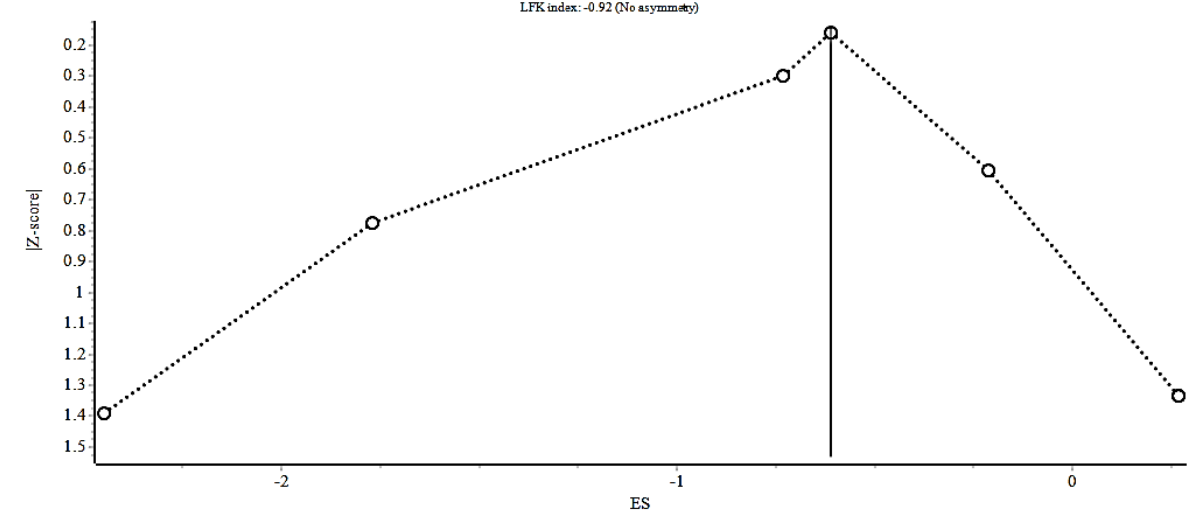

Figure 4 Forest (a) and Doi (b) plots for fatigue index.
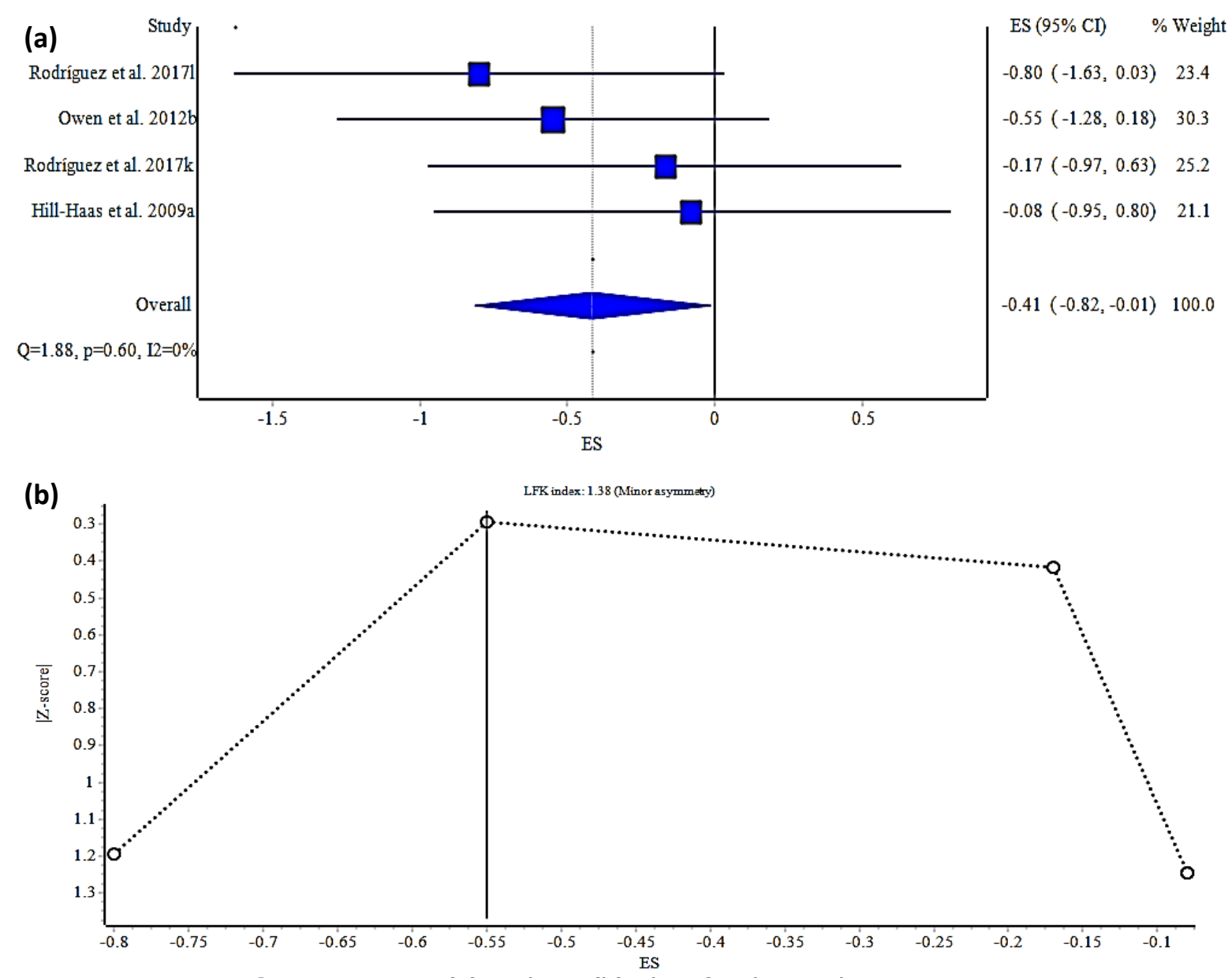

Figure 5 Forest (a) and Doi (b) plots for the total time. 
(a)

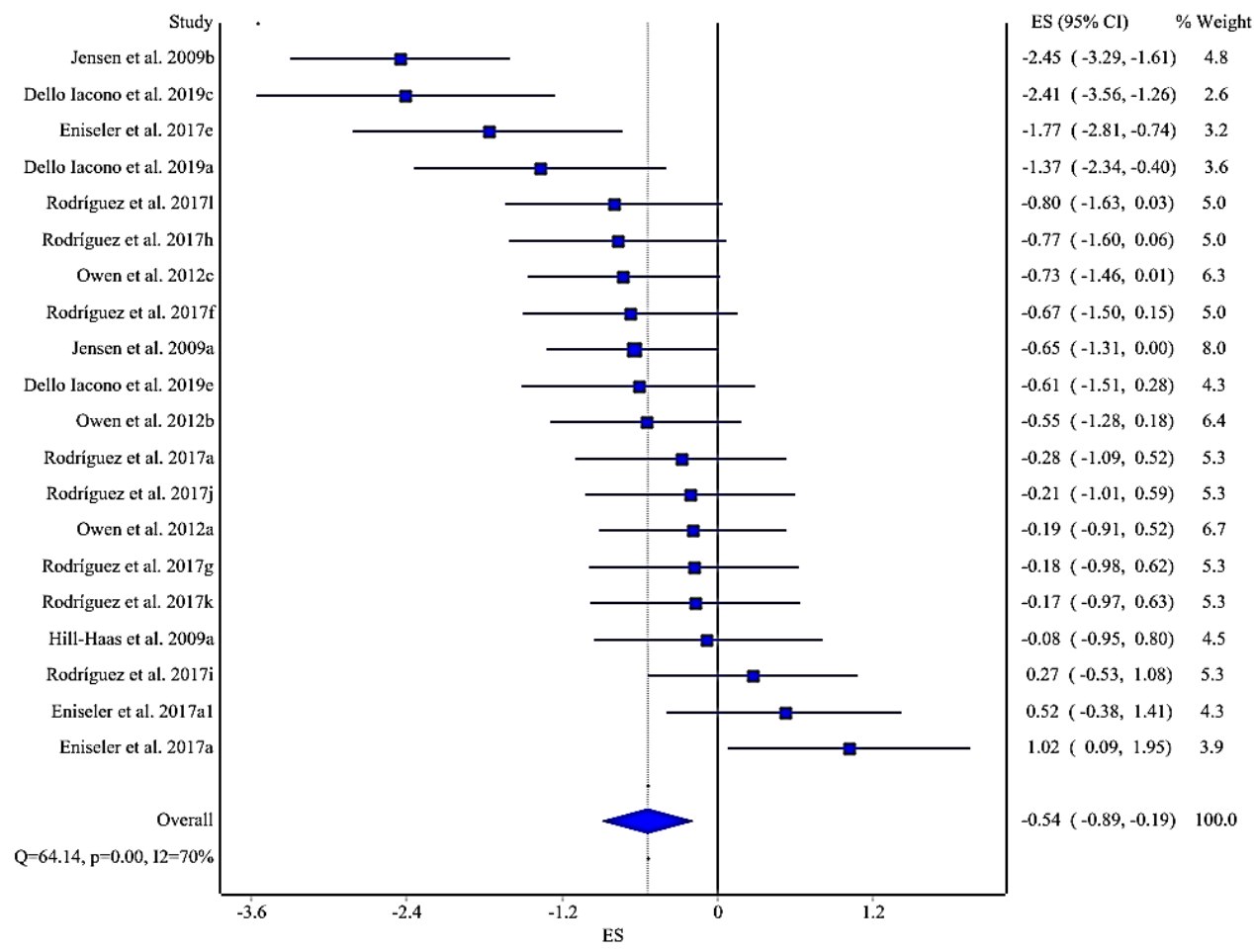

(b)

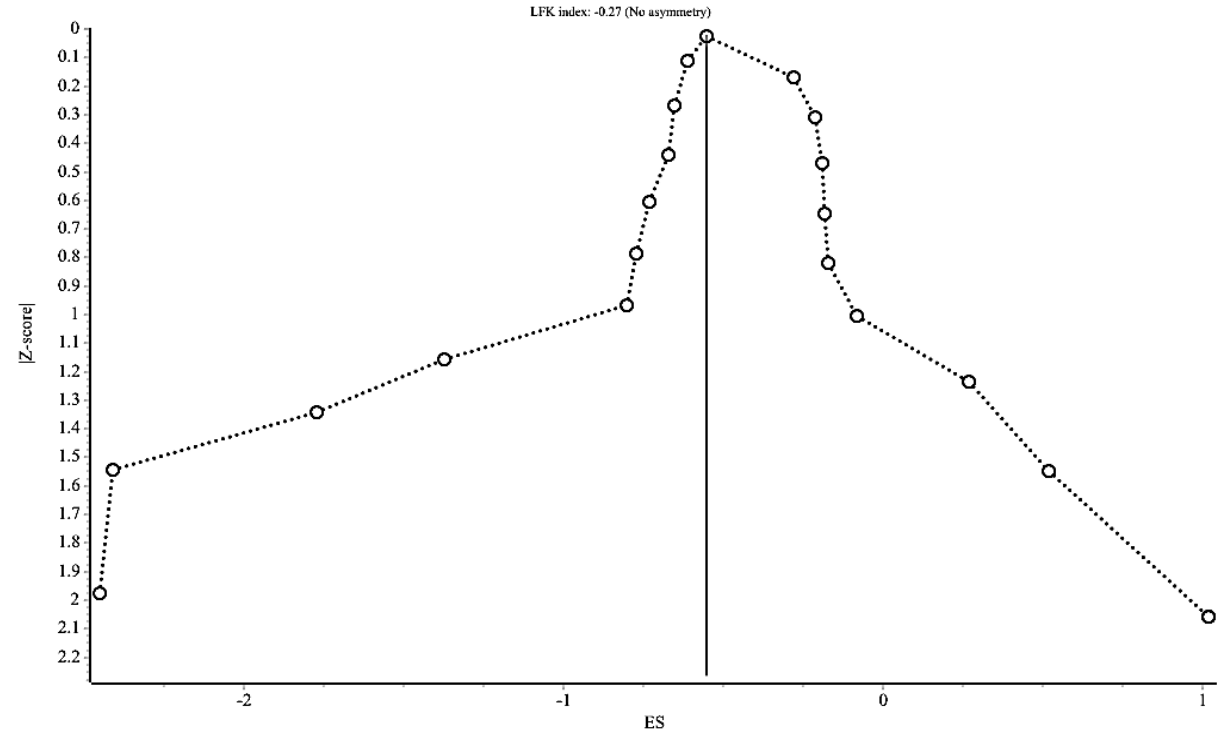

Figure 6 Forest (a) and Doi (b) plots for all subgroups of the small-sided games.

Table 3 Analysis of moderating variables with the fatigue index component in RSA.

\begin{tabular}{lcccc}
\hline Variables & ES (n) & $\boldsymbol{\beta}(\mathbf{9 5 \%} \mathbf{C I})$ & $\mathbf{p ~} \leq$ & $\mathbf{R}^{\mathbf{2}} \mathbf{( \% )}$ \\
\hline Number of weeks & 6 & $-.25(-.47,-.03)$ & .05 & 56.6 \\
Sessions/week & 6 & $.69(.29,1.10)$ & .001 & 82.9 \\
Total sessions & 6 & $.10(-.03, .23)$ & .12 & 26.2 \\
Total sets & 6 & $.04(.02, .06)$ & .01 & 78.5 \\
Recovery/set & 6 & $-.23(-1.36, .89)$ & .68 & 0 \\
Time/session & 6 & $.05(.01, .08)$ & .01 & 67.1 \\
Time/week & 6 & $.01(.00, .01)$ & .05 & 61.6 \\
Total time & 6 & $.00(.00, .00)$ & .05 & 53.5 \\
Field width & 5 & $.13(.04, .21)$ & .01 & 100.0 \\
Field length & 5 & $.08(-.00, .17)$ & .10 & 61.5 \\
Relative area/player $\left(\mathrm{m}^{2}\right)$ & 5 & $.02(-.03, .07)$ & .43 & 0 \\
\hline
\end{tabular}


During SSG training, the most common movements are very high-intensity repetitive running efforts (i.e., sprints), changes of body direction, acceleration, braking, dribbling, and movements that intensify the overall physiological stress. All of these movements can explain the observed improvements in RSA [41, 43]. Additionally, since the nature of RSA is multivariate and is measured through multiple components, the magnitude of the effect for each of them (e.g., best, average, fatigue index, total time) was different. Although they indeed showed a negative $E S$, which means an improvement in performance (the shorter the time, the better the performance), only two RSA variables reached statistical significance (i.e., fatigue index, total time). Similar findings have been reported in team sports where inconsistencies in the results are often observed. These divergences may be explained by different RSA testing protocols or to how changes in the decrease in sprint scores are interpreted, especially in the RSA fatigue index component $[26,44]$.

The studies included in the present metaanalysis used different protocols to measure RSA. Although this variable was not considered as a moderator given its a priori detected heterogeneity, the differences in protocols could influence fatigue, even compromising the running biomechanics $[44,45]$. When analyzing the best time RSA component, despite having improved, it did not reach statistical significance. Cross-sectional studies show that, compared to a real soccer game, SSGs simulate general movement patterns; however, they offer insufficient training stimuli to players for executing high-speed actions [46-48]. A very clear example is demonstrated by Owen, Wong [48] on elite European players. The researchers categorized SSGs into three formats according to the relative area per player: a) short $\left(94 \mathrm{~m}^{2}\right)$, b) medium (184 to $\left.188 \mathrm{~m}^{2}\right)$, and c) long (218 to $336 \mathrm{~m}^{2}$ ). The long SSG format elicited improvements in high-speed actions, but these did not exceed $25.2 \mathrm{~km} \cdot \mathrm{h}^{-1}$, considered a moderate speed since soccer players in a competitive game reach speeds greater than $30 \mathrm{~km} \cdot \mathrm{h}^{-1}$. Therefore, researchers suggest more specific training strategies to develop the RSA sprint $[43,49,50]$.

The RSA average component did not reach statistical significance in the present study. This finding is consistent with previous evidence showing a lack of improvement following SSG; however, this component is enhanced following repeated sprint training, which is associated with an improvement in anaerobic performance $[8,26,43]$. Other studies reported improvements in the average sprint $[1,51]$, with an increase of $3.35 \%$ in the average RSA [1]. These differences could be partially explained by the training category of the sample participating in these studies where amateur players are more likely to achieve higher improvements than professional soccer players [52].

The SSGs significantly improved the RSA total time. The RSA is related to a mixed metabolic disposition [44], and this indicator should be used together with the fatigue index to evaluate the repeated sprint, since it is necessary to contextualize the fatigue indices calculated when evaluating RSA because having less or more fatigue does not always equate to better or worse performance in soccer [53, 54]. Hill-Haas, Dawson [41], did not report improvements in the total sprint, despite introducing a variety of designs of reduced space, enlarging or shortening the field, or using formats of a different number of players ( $70 \%$ were large: 5 vs. 5,7 vs. 7 ), which might explain the fact that these types of formats can decrease the intensity of the exercise.

Significant reductions in the sprint and highspeed actions have previously been reported towards the end of high-level games. These can be explained by the fatigue index, which, according to the results of the present study, show a large ES that coincides with other studies $[26,55,56]$. The fatigue index has been related to aerobic power $[26,57]$ and SSGs provide an adequate stimulus to improve this quality by causing physiological adaptations that facilitate recovery processes [26, 55].

In the present meta-analysis, no effects were found of SSG on RSA according to the relative area (i.e., the ratio of $\mathrm{m}^{2}$ per player) (Table 3). Naturally, a bigger relative space could provide more time and space for players to execute passes and perform other actions [58]. Additionally, it has been shown that at larger field sizes, players are exposed to more running because players have less ball possession and need to run more to close gaps and press in defense when the opponent possess the ball; and in the attack, to open spaces and build a game [59-61]. A practical approach has considered using $\sim 100 \mathrm{~m}^{2}$ for SSGs, while large games generally use $>200 \mathrm{~m}^{2}[48,60]$, because, in large games, a greater total running distance, highintensity running, and many sprints have been observed [59]. Practically in all the studies, a small dimension of SSG was used, ranging from 90 to 165 $\mathrm{m}^{2} /$ player; therefore, it was impossible to discriminate 
between one format and another. Other consideration may be the combination of different reduced space designs in the same study, since, throughout the intervention, the players will be exposed to different physical and technical demands [48]. This could affect the findings of the present meta-analysis because at least two studies used those formats.

Regarding the field's width and length, the width had an impact on the RSA fatigue index. Despite being unable to find an effect of the field length on RSA, in the literature consulted, differences were found in the distance covered at high-intensity and technical actions. A study in players under 15 years of age determined the effects of two different field configurations ( $40 \mathrm{~m} \times 30 \mathrm{~m}$ and $30 \mathrm{~m} \times 40 \mathrm{~m}$ ) with the same relative area per player and playing with goalkeepers [62]. There were more shots on goal during the games played on the $30 \mathrm{~m}$ long $\times 40 \mathrm{~m}$ wide field, and that more passes occurred in the games played on the $40 \mathrm{~m}$ long $\times 30$ wide field. Therefore, it is recommended to use the proportions relative to those of a football match (length/width $=1.46$ ) [62].

An inverse correlation was found between the ES of the RSA fatigue index and the number of weeks of training of SSG (Table 3); for each accumulated week of training, there will be an improvement in the RSA fatigue index. As previously noted, there is a very high influence of the aerobic metabolism on the ability to perform repeated sprints; therefore, the training intensity is a key determinant of mitochondrial content, one of the primary adaptive responses of this type of training [63-65]. Thus, coaches and physical trainers must prioritize programming this variable to ensure greater adaptations. There is evidence indicating substantial improvements following 6 to 12 weeks of training. For example, Jensen, Randers [55], reported a $20.8 \%$ improvement in the RSA fatigue index following a 12-week program with elite soccer players. Owen, Wong del [56], reported improvements of $31.15 \%$ in the fatigue index (even greater than repeated sprint training, 11.56\%) for 6 weeks. Dello Iacono, Beato [66], also found improvements after 8 weeks of training, while others [51,56], with only 4 and 5 weeks, failed to demonstrate an improvement of SSG in the fatigue index.

Concerning the SSG training frequencies, we found that more than twice a week did not reduce the RSA fatigue index, possibly due to exhaustion with a concomitant impaired performance. This argument emerges from the study by Moran, Blagrove [20], who suggested that SSGs, as used to improve endurance performance, can be programmed up to twice a week with adequate recovery between sessions. The study by Rodríguez-Fernández, Sánchez Sánchez [51], included 4 sessions/week, for 6 weeks. No improvements were found in the RSA fatigue index after the SSG intervention. Therefore, coaches must prescribe an appropriate balance between work and recovery to ensure that players can recover from the SSG requirement and improve RSA.

This meta-analysis reports the effect of SSG on RSA and its findings are specific to the sport of men's soccer. Two potential drawbacks of the study were the small number of studies included for analysis and the large heterogeneity between studies, which. Thus, it would be necessary to have a greater number of players to obtain more generalizable results. Demographic characteristics (e.g., different competitive levels) do not allow generalization of the findings to elite soccer players; it seems necessary to design new confirmatory studies, as it is evident the scarce number of studies involving elite professional players. Experimental studies with established relative areas are also necessary to define whether or not there is a development of RSA and to consider other moderating variables, such as the time of measurement (e.g., preseason, season, post-season), the level physical activity of the subjects, age, and game format (number of players).

\section{Conclusion}

In conclusion, the methodological use of the SSG allows the development of the capacity of repeated sprints, while the technique and the tactical elements are trained concomitantly. The RSA components have shown inconsistency in the results, which can be partially explained by the different RSA testing protocols, or by how changes are interpreted, especially in the fatigue index. The fatigue index is related to aerobic power, causing adaptations that facilitate recovery processes. This component can be conditioned negatively if many sessions/weeks are executed and positively if the duration of the intervention lasts for several weeks. Further studies on the effects of SSG are warranted on elite soccer players.

\section{References}

[1] P. Bujalance-Moreno, F. García-Pinillos, P. Latorre-Román, Effects of a small-sided gamebased training program on repeated sprint and 
change of direction abilities in recreationallytrained soccer players, Journa of Sports Medicine and Physical Fitness, 58(7-8) (2018) 1021-1028. DOI | PubMed

[2] O. Girard, A. Mendez-Villanueva, D. Bishop, Repeated-sprint ability - part I: factors contributing to fatigue, Sports Medicine, 41(8) (2011) 673-694. DOI I PubMed

[3] D. Bishop, O. Girard, A. Mendez-Villanueva, Repeated-sprint ability - part II: recommendations for training. Sports Medicine, 41(9) (2011) 741-756. DOI I PubMed

[4] Ermanno Rampinini, Aldo Sassi, Andrea Morelli, Stefano Mazzoni, Maurizio Fanchini, Aaron J Coutts, Repeated-sprint ability in professional and amateur soccer players, Applied Physiology, Nutrition, and Metabolism, 34(6) (2009) 10481054. DOI | PubMed

[5] Matt Spencer, David Bishop, Brian Dawson, Carmel Goodman, Physiological and metabolic responses of repeated-sprint activities:specific to field-based team sports, Sports Medicine, 35(12) (2005) 1025-1044. DOI I PubMed

[6] E. Rampinini, F.M. Impellizzeri, C. Castagna, G. Abt, K. Chamari, A. Sassi, S.M. Marcora, Factors influencing physiological responses to small-sided soccer games, Journal of Sports Sciences, 25(6) (2007) 659-666. DOI I PubMed

[7] Miguel A Campos-Vazquez, Sergio Romero-Boza, Francisco J Toscano-Bendala, Juan A LeonPrados, Luis J Suarez-Arrones, Jose A GonzalezJurado, Comparison of the effect of repeatedsprint training combined with two different methods of strength training on young soccer players, Journal of Strength and Conditioning Research, 29(3) (2015):744-751. DOI | PubMed

[8] D. Ferrari Bravo, F.M. Impellizzeri, E. Rampinini, C. Castagna, D. Bishop, U. Wisloff, Sprint vs. interval training in football, International Journal of Sports Medicine, 29(8) (2008) 668-674. DOI I PubMed

[9] J. Halouani, H. Chtourou, T. Gabbett, A. Chaouachi, K. Chamari, Small-sided games in team sports training: a brief review, Journal of Strength and Conditioning Research, 28(12) (2014) 3594-3618. DOI I PubMed

[10] J. Sanchez-Sanchez, D. Hernández, D. Casamichana, C. Martínez-Salazar, R. RamirezCampillo, J. Sampaio, Heart Rate, Technical Performance, and Session-RPE in Elite Youth Soccer Small-Sided Games Played With Wildcard Players, Journal of Strength and Conditioning
Research, 31(10) (2017) 2678-2685. DOI । PubMed

[11] P. Bujalance-Moreno, P. Latorre-Román, F. García-Pinillos, A systematic review on smallsided games in football players: Acute and chronic adaptations, Journal of Sports Sciences, 37(8) (2019) 921-949. DOI I PubMed

[12] J. Muñoz, D. Castillo, J. Yanci, Análisis de la percepción subjetiva del esfuerzo diferenciado y de la fatiga en distintos formatos de juegos reducidos en fútbol. Revista Iberoamericana de Ciencias de la Actividad Física y el Deporte, 7(2) (2018) 14-28. DOI

[13] D. Casamichana, J. Castellano, J. CallejaGonzalez, J. San Román, C. Castagna, Relationship between indicators of training load in soccer players, Journal of Strength and Conditioning Research, 27(2) (2013) 369-374. DOI | PubMed

[14] M. Brandes, A. Heitmann, L. Müller, Physical responses of different small-sided game formats in elite youth soccer players, Journal of Strength and Conditioning Research, 26(5) (2012) 13531360. DOI I PubMed

[15] A. Dellal, S. Hill-Haas, C. Lago-Penas, K. Chamari, Small-sided games in soccer: amateur vs. professional players' physiological responses, physical, and technical activities, Journal of Strength and Conditioning Research, 25(9) (2011) 2371-81. DOI I PubMed

[16] J. Batista, B. Goncalves, J. Sampaio, J. Castro, E.Abade, B. Travassos, The influence of coaches' instruction on technical actions, tactical behaviour, and external workload in football small-sided games, Montenegrin Journal of Sports Science \& Medicine, 8(1) (2019) 29-36. DOI

[17] J. Christopher, M. Beato, A.T. Hulton, Manipulation of exercise to rest ratio within set duration on physical and technical outcomes during small-sided games in elite youth soccer players, Human Movement Science, 48 (2016) 1-6. DOI | PubMed

[18] A.M. Safania, R. Alizadeh, M. Nourshahi, A comparison of small-side games and interval training on same selected physical fitness factors in amateur soccer players. Journal of Social Sciences, 7(3) (2011) 349-353. DOI

[19] D. Fransson, T. Schmidt Nielsen, K. Olsson, T. Christensson, P.S. Bradley, I.G. Fatouros, P. Krustrup, N. Baastrup Nordsborg, M. Mohr, Skeletal muscle and performance adaptations to 
high-intensity training in elite male soccer players: speed endurance runs versus smallsided game training, European Journal of Applied Physiology, 118(1) (2018) 111-121. DOI । PubMed

[20] J. Moran, R.C. Blagrove, B. Drury, J.F.T. Fernandes, K. Paxton, H. Chaabene, R. RamirezCampillo, Effects of Small-Sided Games vs. Conventional Endurance Training on Endurance Performance in Male Youth Soccer Players: A Meta-Analytical Comparison, Sports Medicine, 49(5) (2019) 731-742. DOI I PubMed

[21] M. Glaister, G. Howatson, J.R. Pattison, G. McInnes, The reliability and validity of fatigue measures during multiple-sprint work: an issue revisited, Journal of Strength and Conditioning Research, 22(5) (2008) 1597-1601. DOI । PubMed

[22] J.L. Oliver, Is a fatigue index a worthwhile measure of repeated sprint ability?, Journal of Science and Medicine in Sport, 12(1) (2009) 2023. DOI | PubMed

[23] J. Bangsbo, (1994), Fitness Training in Football, A Scientific Approach, Copenhagen: Bagsvared.

[24] C.B. Wragg, N.S. Maxwell, J.H. Doust, Evaluation of the reliability and validity of a soccer-specific field test of repeated sprint ability, European Journal of Applied Physiology, 83(1) (2000) 7783. DOI | PubMed

[25] M. Fitzsimons, B. Dawson, D. WARD, A.W. Wilkinson, B. DAWSON-HUGHES, D Ware, M.A. Fitzsimons, M FitzSimons, B. DAWSON, A. Wilkinson, M. Fitzsimons, D. WARE, A. WILKINSON, M. Fitzsimmons, D Ward, B Dawson-Hughes, A. Wilkinson, Cycling and running tests of repeated sprint ability, Australian Journal of Science \& Medicine in Sport, 25(1993) 82-87.

[26] N. Eniseler, Çağatay Şahan, Ilker Özcan, and Kıvanç Dinler, High-Intensity Small-Sided Games versus Repeated Sprint Training in Junior Soccer Players, Journal of Human Kinetics, 60 (2017) 101-111. DOI | PubMed

[27] David Moher, Larissa Shamseer, Mike Clarke, Davina Ghersi, Alessandro Liberati, Mark Petticrew, Paul Shekelle, Lesley A Stewart \& PRISMA-P Group, Preferred reporting items for systematic review and meta-analysis protocols (PRISMA-P) 2015 statement, Systematic Reviews, 4(1) (2015) 1. DOI

[28] C.G. Maher, C. Sherrington, R.D. Herbert, A.M. Moseley, M. Elkins, Reliability of the PEDro Scale for Rating Quality of Randomized Controlled Trials. Physical Therapy, 83(8) (2003) 713-721. DOI | PubMed

[29] E. Lee, M. Dobbins, K. Decorby, L. McRae, D. Tirilis, H. Husson, An optimal search filter for retrieving systematic reviews and meta-analyses, BMC Medical Research Methodology, 12(1) (2012) 51. DOI I PubMed

[30] M. Borenstein, L.V. Hedges, J. Higgins, H. Rothstein, Introduction to meta-analysis2009, United Kingdom: John Wiley \& Sons.

[31] J. Cohen, A power primer, Psychological bulletin, 112(1) (1992) 155-159. DOI I PubMed

[32] R. DerSimonian, N. Laird, Meta-analysis in clinical trials, Controlled clinical trials, 7(3) (1986) 177188. DOI I PubMed

[33] L. Furuya-Kanamori, J.J. Barendregt, S.A.R. Doi, A new improved graphical and quantitative method for detecting bias in meta-analysis, International Journal of Evidence-Based Healthcare, 16(4) (2018) 195-203. DOI । PubMed

[34] J.A. C Sterne, A.J. Sutton, J.P.A. Ioannidis, N. Terrin, D.R. Jones, J. Lau, J. Carpenter, G. Rücker, R.M. Harbord, C.H. Schmid, J. Tetzlaff, J.J. Deeks, J. Peters, P. Macaskill, G. Schwarzer, S. Duval, D.G. Altman, D. Moher, J.P.T. Higgins, Recommendations for examining and interpreting funnel plot asymmetry in metaanalyses of randomised controlled trials, BMJ, 343 (2011) d4002. DOI I PubMed

[35] W.G. Cochran, The combination of estimates from different experiments, Biometrics, 10(1) (1954) 101-129. DOI

[36] J.P. Higgins, S.G. Thompson, J.J. Deeks, D.G. Altman, Measuring inconsistency in metaanalyses, BMJ, 327(7414) (2003) 557-560. DOI I PubMed

[37] G.A. Kelley, K.S. Kelley, Systematic reviews and meta-analysis in nutrition research, British Journal of Nutrition, 122(11) (2019) 1279-1294. DOI I PubMed

[38] L. Furuya-Kanamori, S.A. Doi. LFK: Stata module to compute LFK index and Doi plot for detection of publication bias in meta-analysis, Statistical Software Components S458762. 2020; Available from:

https://ideas.repec.org/c/boc/bocode/s458762.ht $\mathrm{ml}$

[39] B.C. Wallace, M.J. Lajeunesse, G. Dietz, I.J. Dahabreh, T.A. Trikalinos, C.H. Schmid, J. Gurevitch, OpenMEE: Intuitive, open-source 
software for meta-analysis in ecology and evolutionary biology, Society Methods in Ecology and Evolution, 8 (2017) 941-947. DOI

[40] M. Buchheit, P.B. Laursen, J. Kuhnle, D. Ruch, C. Renaud, S. Ahmaidi, Game-based training in young elite handball players, International Journal of Sports Medicine, 30(4) (2009) 251258. DOI | PubMed

[41] S.V. Hill-Haas, B.T. Dawson, A.J. Coutts, G.J. Rowsell, Physiological responses and timemotion characteristics of various small-sided soccer games in youth players, Journal of Sports Sciences, 27(1) (2009) 1-8. DOI I PubMed

[42] F.M. Impellizzeri, E. Rampinini, C. Castagna, D. Bishop, D. Ferrari Bravo, A. Tibaudi, U. Wisloff, Validity of a repeated-sprint test for football, International Journal of Sports Medicine, 29(11) (2008) 899-905. DOI I PubMed

[43] M. Buchheit, A. Mendez-villanueva, B.M. Simpson, P.C. Bourdon, Repeated-sprint sequences during youth soccer matches, International Journal of Sports Medicine, 31(10) (2010) 709-716. DOI I PubMed

[44] D.B. Pyne, P.U. Saunders, P.G. Montgomery, A.J. Hewitt, K. Sheehan, Relationships between repeated sprint testing, speed, and endurance, Journal of Strength and Conditioning Research, 22(5) (2008) 1633-1637. DOI I PubMed

[45] S. Ratel, C.A. Williams, J. Oliver, N. Armstrong, Effects of age and recovery duration on performance during multiple treadmill sprints, International Journal of Sports Medicine, 27(1) (2006) 1-8. DOI I PubMed

[46] 46. D. Casamichana, J. Castellano, C. Castagna, Comparing the physical demands of friendly matches and small-sided games in semiprofessional soccer players, Journal of Strength and Conditioning Research, 26(3) (2012) 837-843. DOI I PubMed

[47] T. Gabbett, D. Jenkins, B. Abernethy, Gamebased training for improving skill and physical fitness in team sport athletes, International Journal of Sports Science \& Coaching, 4(2) (2009) 273-283. DOI

[48] A.L. Owen, D.P. Wong, D. Paul, A. Dellal, Physical and technical comparisons between various-sided games within professional soccer, International Journal of Sports Medicine, 35(4) (2014) 286-292. DOI I PubMed

[49] S.V. Hill-Haas, A.J. Coutts, G.J. Rowsell, B.T. Dawson, Generic versus small-sided game training in soccer, International Journal of Sports
Medicine, 30(9) (2009) 636-642. DOI | PubMed

[50] L. Radziminski, P. Rompa, W. Barnat, R. Dargiewicz, Z. Jastrzebski, A comparison of the physiological and technical effects of highintensity running and small-sided games in young soccer players, International Journal of Sports Science \& Coaching, 8(3) (2013) 455466. DOI

[51] A. Rodríguez-Fernández, J. Sánchez Sánchez , J.A. Rodríguez-Marroyo, D. Casamichana, J.G. Villa, Effects of 5-week pre-season small-sidedgame-based training on repeat sprint ability, Journal of Sports Medicine and Physical Fitness, 57(5) (2017) 529-536. DOI I PubMed

[52] K. Chamari, Y. Hachana, F. Kaouech, R. Jeddi, I. Moussa-Chamari, U. Wisløff, Endurance training and testing with the ball in young elite soccer players, British Journal of Sports Medicine, 39(1) (2005) 24-28. DOI I PubMed

[53] M. Mohr, P. Krustrup, J. Jung Nielsen, L. Nybo, M. Krøyer Rasmussen, C. Juel, J. Bangsbo, Effect of two different intense training regimens on skeletal muscle ion transport proteins and fatigue development, American Journal of PhysiologyRegulatory, Integrative and Comparative Physiology, 292(4) (2007) R1594-R1602. DOI I PubMed

[54] S. Racinais, S. Perrey, R. Denis, D. Bishop, Maximal power, but not fatigability, is greater during repeated sprints performed in the afternoon, Chronobiology International, 27(4) (2010) 855-864. DOI I PubMed

[55] J.M. Jensen, M.B. Randers, P. Krustrup and J. Bangsbo, Effect of additional in-season aerobic high-intensity drills on physical fitness of elite football players, Journal of Sports Science and Medicine, 6(10) (2007) 79. DOI | PubMed https://www.jssm.org/volumesuppls/iss1/cap/jss m-suppls-10.pdf

[56] A.L. Owen, D.P. Wong, D. Paul, A. Dellal, Effects of a periodized small-sided game training intervention on physical performance in elite professional soccer, Journal of Strength and Conditioning Research, 26(10) (2012) 2748-54. DOI | PubMed

[57] K.A. Burgomaster, S.C. Hughes, G.J.F. Heigenhauser, S.N. Bradwell, M.J. Gibala, Six sessions of sprint interval training increases muscle oxidative potential and cycle endurance capacity in humans, Journal of Applied Physiology, (1985), 98(6) (2005) 1985-1990. DOI | PubMed 
[58] F. Clemente, H. Sarmento, The effects of smallsided soccer games on technical actions and skills: A systematic review, Human Movement, 21(3) (2020) 100-119. DOI

[59] D. Casamichana,J. Castellano, Time-motion, heart rate, perceptual and motor behaviour demands in small-sides soccer games: effects of pitch size, Journal of Sports Sciences, 28(14) (2010) 1615-1623. DOI I PubMed

[60] F.M. Clemente, Associations between wellness and internal and external load variables in two intermittent small-sided soccer games, Physiology and Behavior, 197(2018) 9-14. DOI | PubMed

[61] D. Coutinho, B. Gonçalves, B. Figueira, E. Abade, R. Marcelino, J. Sampaio, Typical weekly workload of under 15 , under 17 , and under 19 elite Portuguese football players, Journal of Sports Sciences, 33(12) (2015) 1229-1237. DOI I PubMed

[62] H. Folgado, J. Bravo, P. Pereira, J. Sampaio, Towards the use of multidimensional performance indicators in football small-sided games: the effects of pitch orientation, Journal of Sports Sciences, 37(9) (2019) 1064-1071. DOI | PubMed

[63] D.J. Bishop, J. Botella, A.J. Genders, M.J-C. Lee, N.J. Saner, J. Kuang, X. Yan, C. Granata, HighIntensity Exercise and Mitochondrial Biogenesis: Current Controversies and Future Research Directions, Physiology (Bethesda), 34(1) (2019) 56-70. DOI | PubMed

[64] D.J. Bishop, J. Botella, C. Granata, Rebuttal from David J. Bishop, Javier Botella and Cesare Granata, Journal of Physiology, 597(16) (2019) 4121-4122. DOI | PubMed

[65] M.J. MacInnis, L.E. Skelly, M.J. Gibala, CrossTalk proposal: Exercise training intensity is more important than volume to promote increases in human skeletal muscle mitochondrial content, Journal of Physiology, 597(16) (2019) 41114113. DOI I PubMed

[66] A. Dello Iacono, M. Beato, V. Unnithan, Comparative Effects of Game Profile-Based Training and Small-Sided Games on Physical Performance of Elite Young Soccer Players, Journal of Strength and Conditioning Research, (2019). DOI I PubMed
Acknowledgement

We thank Dr. J. Jiménez-Díaz for her support during the study.

Funding

Nil.

\section{Authors Contribution}

Both the authors equally contributed to this work.

\section{Ethics Approval}

Not Applicable.

\section{Conflict of interest}

Nil

Availability of data and material No additional data are available

Informed consent

Not Applicable

\section{About The License}

(C) The author(s) 2020. The text of this article is open access and licensed under a Creative Commons Attribution 4.0 International License 